\title{
DIREITOS DOS ANIMAIS E SUA TUTELA NO BRASIL: AVANÇOS E RETROCESSOS
}

ANIMAL RIGHTS AND THEIR PROTECTION IN BRAZIL: ADVANCES AND RETROCESSES

\author{
Lívia Gaigher Bósio Campello ${ }^{1}$ \\ Patrícia Estolano Francelino ${ }^{2}$
}

\begin{abstract}
Resumo
As discussões sobre a objetificação do animal não-humano emergiram na sociedade e resultaram na necessidade de implementação de mudanças no ordenamento jurídico brasileiro. Com efeito, a colisão de interesses entre os tradicionais eventos culturais e o bem-estar dos animais neles envolvidos foi destaque nos últimos anos e culminaram na ponderação de interesses, ora em favor dos animais, mas também em favor de antropocêntricos interesses humanos. Destarte, este estudo se revela importante ao fomentar a produção científica em prol daqueles que não possuem voz ativa para defender sua existência como seres vivos, sensíveis e detentores de direitos. Além disso, torna-se primordial, sobretudo, frente aos recentes abalos normativos que retrocedem a discussão, a exemplo da Emenda Constitucional 96, de 06.06.2017, que categoriza como não crueis as práticas desportivas que envolvem animais, contanto que sejam caracterizadas como manifestações culturais, inserindo o controvertido $\S$ $7^{\circ}$ ao artigo 225 da Constituição Federal de 1988. Em vista disso, o objetivo geral desta pesquisa é investigar a possibilidade de uma tutela mais rígida sobre o bem-estar do animal não-humano no ordenamento jurídico nacional em face à proteção constitucional da manifestação cultural dos cidadãos brasileiros. Para que os resultados sejam atingidos, $o$ método de pesquisa utilizado tem por base a pesquisa exploratória e descritiva, bibliográfica e documental, com emprego do raciocínio dedutivo.
\end{abstract}

\footnotetext{
${ }^{1}$ Pós-Doutora em Direito do Estado pela Universidade de São Paulo (USP), Doutora em Direito das Relações Econômicas e Internacionais pela Pontifícia Universidade Católica de São Paulo (PUC/SP) e Mestre em Políticas Públicas e Processo pelo Centro Universitário Fluminense (UNIFLU). Professora da graduação e mestrado na Faculdade de Direito (FADIR/UFMS). Coordenadora do Programa de Pós-Graduação em Direitos Humanos (PPGD/UFMS). Coordenadora local do Programa de Doutorado Interinstitucional (DINTER - USP/UFMS). Líder do Grupo de Pesquisa "Direitos Humanos, Meio Ambiente e Desenvolvimento Sustentável Global" (UFMS/CNPq). Coordenadora do Projeto de Pesquisa "Cooperação Internacional e Meio Ambiente" (Fundect/MS). Editora-chefe da Revista Direito UFMS. Associada ao Conselho Nacional de Pesquisa e PósGraduação (CONPEDI) desde 2005. Filiada à Sociedade Brasileira para o Progresso da Ciência (SBPC) desde 2011.

2 Graduada em Medicina Veterinária pela Universidade Federal de Mato Grosso (UFMT), Sinop - MT, Brasil. Inscrita no Conselho Regional de Medicina Veterinária do estado de Mato Grosso do Sul. Acadêmica de Direito pela Universidade Federal de Mato Grosso do Sul (UFMS), Campo Grande - MS, Brasil. Membro do Grupo de Pesquisa "Direitos Humanos, Meio Ambiente e Desenvolvimento Sustentável Global" - (CNPq), Campo Grande - MS, Brasil. Foi bolsista PIBIC/UFMS no projeto de pesquisa "Direitos dos animais na era do desenvolvimento sustentável global" do qual resultou o presente artigo. Residente em Zoonoses e Saúde Pública pelo Programa de Residência em Saúde em Medicina Veterinária (UFMS), Campo Grande - MS, Brasil.
} 
Palavras-chave: direito à cultura; direitos dos animais; colisão de interesses; proibição de retrocesso.

\begin{abstract}
Discussions about the objectification of the non-human animal emerged in society and resulted in the need to implement changes in the Brazilian legal system. Indeed, the collision of interests between traditional cultural events and the welfare of the animals involved in them has been highlighted in recent years and culminated in the balance of interests, sometimes in favor of animals, but also in favor of anthropocentric human interests. Thus, this study proves to be important in fostering scientific production in favor of those who do not have an active voice to defend their existence as living, sensitive and rights-holders. In addition, it is essential, above all, in view of the recent normative shocks that go back to the discussion, as in the case of Constitutional Amendment 96, of 06.06.2017, which does not categorizes sports practices involving animals as cruel, if they are characterized as cultural manifestations, inserting the controversial $\S 7$ to article 225 of the 1988 Federal Constitution. In view of this, the general objective of this research is to investigate the possibility of stricter protection over the welfare of non-human animal in the national legal system in view of the constitutional protection of the cultural manifestation of Brazilian citizens. In order for the results to be achieved, the research method used is based on exploratory and descriptive, bibliographic and documentary research, using deductive reasoning.
\end{abstract}

Keywords: right to culture; animal rights; collision of interests; setback ban.

\title{
1. INTRODUÇÃO
}

É possível considerar que por séculos os seres humanos e animais coexistem no planeta sob uma relação que permeia desde o mutualismo até uma exploração abusiva. Imbuídos por uma consciência designada racional, humanos administram a fauna e flora como julgam conveniente, ou seja, para seu próprio benefício, com intuito de sanar suas necessidades físicas (saúde e alimentação); e psicológicas (esporte e entretenimento), ainda que estas ocorram com o sofrimento de outras espécies, justificadas na maior parte das vezes como até mesmo um mal necessário.

As discussões sobre a objetificação do animal não-humano emergem na sociedade e culminam também na necessidade de mudanças no ordenamento jurídico brasileiro. Vários autores internacionais já se dedicaram sobre o tema como Peter Singer, Tom Regan, Jeremy Bentham, Martha Nussbaum, dentre muitos outros. No Brasil, vários estudos foram elaborados, por exemplo, sob a liderança de Heron Gordilho. Mas, ainda se faz primordial fomentar a produção científica em prol daqueles que não possuem voz ativa para defender sua existência como seres vivos, sensíveis e detentores de direitos. E, de tal maneira, cabe também à comunidade acadêmica munir cientificamente a discussão, com objetivo de extrair do plano valorativo e incluir os direitos dos animais no plano real da estrutura jurídica nacional. 
Sabe-se que conflitos importantes afloram quando se têm, no caso, valores constitucionais em tensão: o direito à manifestação cultural e ao lazer, em afronta ao direito dos animais contra tratamentos crueis, haja vista que estão previstos na Constituição brasileira direitos fundamentais como o acesso à cultura, ao esporte, ao lazer e ao entretenimento, bem como os direitos dos animais.

Com efeito, esta pesquisa tem como intuito realizar uma avaliação crítica das formas pelas quais o Brasil, conforme a distribuição de competências legislativas e executivas estabelecidas pelo pacto federativo, produz e aplica normas de proteção dos animais em seu território nacional à luz do conflito com o direito constitucional fundamental à cultura e ao entretenimento.

Desse modo, o presente trabalho se torna imprescindível para uma evolução da temática, tanto para auxiliar no debate sobre a conservação da dignidade de todas as espécies quanto para a conscientização do valor moral e real da manutenção da vida sob todas as suas formas.

Questiona-se: como salvaguardar o direito do animal não humano à proteção contra maus tratos pode ser garantido frente ao conflito com determinados interesses culturais arraigados na sociedade brasileira? A partir dessa indagação, tem-se como objetivo geral estudar a possibilidade de uma tutela mais rígida sobre o bem-estar animal não-humano no ordenamento jurídico nacional, a partir do $\S 1^{\circ}$, inciso VII do artigo 225 da Constituição Federal de 1988. Desse modo, pretende-se analisar a proteção jurídica constitucional do direito animal a não crueldade com base no princípio da solidariedade entre espécies, bem como aprofundar o exame sobre o conflito social e jurídico entre a garantia do bem-estar animal e o uso de seres vivos em movimentos culturais para a satisfação do direito humano ao acesso à cultura e ao entretenimento. Para que os resultados sejam atingidos, o método de pesquisa utilizado tem por base a pesquisa exploratória e descritiva, bibliográfica e documental, com emprego do raciocínio dedutivo.

\section{A PROTEÇÃO ANIMAL EM FACE À CRUELDADE: TÊNUE LIMITE ENTRE O BEM-ESTAR E MAUS-TRATOS NA UTILIZAÇÃO DE ANIMAIS EM MANIFESTAÇÕES CULTURAIS}

A Declaração da Organização das Nações Unidas para a Educação, Ciência e a Cultura - UNESCO é o grande marco do Direito dos Animais:

Artigo $1^{\circ}$ : Todos os animais nascem iguais diante da vida, e têm o mesmo direito à existência. 
Artigo $2^{\circ}$ :

a) Cada animal tem direito ao respeito.

b) O homem, enquanto espécie animal, não pode atribuir-se o direito de exterminar os outros animais, ou explorá-los, violando esse direito. Ele tem o dever de colocar a sua consciência a serviço dos outros animais.

c) Cada animal tem direito à consideração, à cura e à proteção do homem.

Artigo $3^{\circ}$ :

a) Nenhum animal será submetido a maus-tratos e a atos cruéis. [...]

Artigo $10^{\circ}$ : Nenhum animal deve ser usado para divertimento do homem. A exibição dos animais e os espetáculos que utilizem animais são incompatíveis com a dignidade do animal.

Evidencia-se por intermédio dos dispositivos que cabe ao ser humano o dever de colocar sua consciência a serviço dos animais, ou seja, incumbe à racionalidade humana o papel de preservar, proteger e respeitar as demais espécies. Além do mais, o documento também deixa manifesto em seu artigo 10 que "nenhum animal deve ser usado para divertimento do homem. A exibição dos animais e os espetáculos que utilizem animais são incompatíveis com a dignidade do animal.”, não sendo passível a utilização de seres vivos em modalidades cujo fim seja a satisfação de interesses antropocêntricos e vinculados aos prazeres do entretenimento em face do bem-estar e da dignidade de subsistência de outros seres vivos.

De tal modo, Chalfun (2014) compreende que o sistema antropocêntrico "põe o homem como centro de todo o universo, e, assim, toda proteção, preocupação com a natureza, com os animais, possui como objetivo apenas o homem, ele é o centro e a medida de todas as coisas, todo restante não possui qualquer valor em si" o que obstaculiza a ascensão dos valores intrínsecos aos seres vivos e, principalmente, relativiza conceitos vinculados a tutela jurídica que resguarda o direito ao não sofrimento das demais espécies.

Estabelecer critérios que delimitam os limites da crueldade praticada contra os seres vertebrados é, hodiernamente, um dos grandes desafios que pairam sob a luta pela proteção e garantia dos direitos dos animais; tendo em vista que estes são subjugados como meros seres sob domínio humano e a mercê do antropocêntrico conceito de sofrimento.

Com efeito, Peter Singer elucida em sua obra "Libertação Animal" (2010) o início de uma incorporação do princípio da igualdade no sistema ético-moral das relações entre espécies, ressaltando que "se um ser sofre, não pode haver justificativa moral para recusar ter em conta esse sofrimento. Independentemente da natureza do ser, o princípio da igualdade exige que ao seu sofrimento seja dada tanta consideração como ao sofrimento semelhante [...]”.

Segundo Gordilho (2018) os animais "são considerados seres sensíveis ou sencientes e, por esta condição, merecem uma proteção diferenciada em nosso ordenamento jurídico.”. Nesse sentido, denomina-se "senciente" (de senciência: conceito que combina os termos 
"sensibilidade" e "consciência") o organismo vivo que não apenas representa reações orgânicas ou físico-químicas aos estímulos que afetam o seu corpo (sensibilidade), mas também percebe esses estímulos como estados mentais positivos ou negativos (consciência). É, portanto, um indício de que existe um "eu" - nos animais - que vivencia e experimenta sensações. É o que diferencia indivíduos vivos de "meras coisas vivas" (como, por exemplo, as bactérias, as plantas, etc.).

Portanto, ao se determinar o domínio dos animais sob a ótica antropocêntrica de um conceito de racionalidade, percepção e sensibilidade, descaracteriza-se o entendimento científico de um ser senciente. Ao partirmos pelas evidências clássicas do sofrimento pelo sentido da dor física, é possível confirmar a correspondência humano animal no que diz respeito à susceptibilidade fisiológica, tendo em vista que esta é uma idiossincrasia pertencente tanto a animais humanos quanto aos não humanos, pois está ligada diretamente a condição fundamental de sobrevivência.

Ademais, o estado complexo da dor transborda os limites físicos e acende, sobretudo, respostas psíquicas nos seres vertebrados. Desse modo, a interação ambiental, por meio de seus diversos estímulos, implicam diretamente no bem-estar biopsicossocial, humano e animal. As sombras sobre a questão encontram-se na determinação e avaliação do nível de dor suportada pelos animais tidos como seres não racionais, já que estes não são detentores de consciência e não são capazes de exteriorizar verbalmente o estado de agonia físiopsicológica.

Nessa corrente, o estudo mais acurado sobre o bem-estar animal dialoga com os objetivos de melhor atender e avaliar a qualidade de vida dos indivíduos das mais variadas espécies; o que possibilita a tomada de medidas, elaboração de protocolos e normas que estabeleçam a harmonia entre a interação humano animal excluindo-se o caráter antropocêntrico dessa relação. Desse modo, mostra-se coerente que para que se alcance a otimização e que se atinja a determinação dos animais como seres sencientes que são, é de estrito dever humano racionalizar os conhecimentos que respaldam a temática e respeitar as condições e os limites que imperam sobre sua interação ambiental como um todo.

Avanços normativos quanto a determinação de conceitos corroboram com a consolidação dos fundamentos que se harmonizam pela proteção do direito animal; assim como substanciado pela Resolução ${ }^{\circ}$ 1.236, publicada no Diário Oficial pelo Conselho Federal de Medicina Veterinária no ano de 2018, que estabelece a definição e diferenciação de maustratos, crueldade e abusos contra os animais, dispondo como essência a pacificação e uniformização do uso e identificação destes termos, ora relativizados. 
Ainda sobre a evolução dos conceitos que vislumbram pela tutela do direito animal, Campello (2018) deixa inequívoca a atual vivência em uma era de direitos mais que dinâmicos, sendo estas ferramentas de transformação da realidade nacional e internacional. E, diante da existência de conflitos principiológicos que ocorrem no ordenamento jurídico nacional, faz-se basilar a interposição da racionalidade humana sob a vertente do princípio da solidariedade entre espécies, utilizando da suposta superioridade destes como um instrumento equiparador em favor dos demais animais não humanos, seres incapazes de manifestar-se em sua defesa.

Mesmo que com tímidos avanços, ainda observa-se a fragilidade do conceito de crueldade, posta de forma indeterminada pela Constituição Federal, que atribui ao Poder Judiciário a função de interpretar e apreciar sobre o assunto, não sendo concebível que tais considerações voltem-se para as margens do atraso atinente tanto aos direitos dos animais quanto a proteção ambiental, de modo geral. Neste diapasão, Rodrigues (2017) corrobora com tal parâmetro ao afirmar que o Supremo Tribunal Federal tem a prerrogativa hermenêutica de dar alcance e sentido às normas, de realizar o seu papel, sendo necessária e primordial a ruptura com o paradigma antropocêntrico e capitalista de proteção, para que assim seja alcançada a defesa e proteção da vida, sob todas as suas formas, contra os perversos interesses humanos.

Assegurado pela Constituição Federal de 1988, o direito a um ambiente ecologicamente equilibrado é um direito fundamental que deve ser garantido pelo Estado, tendo em vista o seu impacto direto no princípio da Dignidade da Pessoa Humana, afetando tanto os seres humanos quanto os animais não humanos. Nesta toada, Sarlet (2017, p. 84) defende a existência de uma dignidade que transcende os valores humanos ao destacar que:

A atribuição de dignidade a outras formas de vida ou à vida em termos gerais transporta a ideia de respeito e responsabilidade que deve pautar o comportamento do ser humano para com tais manifestações existenciais. Nesse contexto, para além de uma compreensão especista da dignidade, que parece cada vez mais frágil diante do quadro existencial contemporâneo e dos novos valores culturais de matriz ecológica, deve-se avançar com as construções morais e jurídicas no sentido de ampliar o espectro de incidência do princípio da dignidade para além do círculo humano, alcançando também outras formas de vida e a Natureza em si.

Por conseguinte, compreende-se que a necessidade de se atribuir o princípio da Dignidade às demais formas de vida é, portanto, advinda dos novos valores ecológicos que permeiam a sociedade atual. Quando se atribui a valorização intrínseca aos seres vivos, reconhecendo estes como sujeitos - seres com valência em si mesmo - não é concebível a objetificação das espécies não humanas ocorra para satisfação de frívolas necessidades 
humanas. A partir do princípio da solidariedade entre espécies e do princípio da Dignidade além da vida humana, observa-se a necessidade de uma modulação do ordenamento jurídico interno, sob a luz destas projeções principiológicas, aos casos em concreto que colocam em cheque a proteção da existência digna da vida não humana em face dos direitos humanos ao acesso às manifestações culturais e ao entretenimento.

\section{PONDERAÇÃO DE VALORES: CONFLITO DE PRINCÍPIOS CONSTITUCIONAIS}

No Brasil, a utilização de animais em práticas desportivas, realçada por um perfil de manifestação cultural, está intrinsecamente ligada à população. E, além desses eventos serem utilizados pelo espectro do entretenimento, a instrumentalização de animais ocorre, também, com um propósito econômico e mercadológico. De tal modo, a Emenda Constitucional 96, de 6.6.2017, aduz como não crueis as práticas desportivas predispostas aos animais, contando com que estas sejam caracterizadas como manifestações culturais, como prescrito no $\S 1^{\circ}$, inciso VII, do art. 225 da Constituição Federal de 1988, atendendo ao interesse social humano de manter-se sobre o gozo de suas tradições, ainda que estas sejam sustentadas pela objetificação e sofrimento de outras espécies.

Transcrito pela Constituição Federal de 1988, o direito humano de manifestar-se culturalmente está respaldado pelo artigo 215, em seu caput, a seguinte redação "O Estado garantirá a todos o pleno exercício dos direitos culturais e acesso às fontes da cultura nacional, e apoiará e incentivará a valorização e a difusão das manifestações culturais.”. Na mesma toada, o artigo 217, $\S 3^{\circ}$ da Constituição Federal de 1988, prevê que cabe ao "Poder Público incentivará o lazer, como forma de promoção social". Sob a luz dos princípios e Direitos Fundamentais, o constituinte deixou resguardado como mens legis o direito dos seres humanos de se divertirem, compondo, assim, o ensejo de um equilíbrio orgânico social de um bem-estar individual e, consequentemente, coletivo.

Desse modo, a utilização de animais em manifestações culturais, que satisfazem necessidades humanas, coloca em colisão princípios constitucionais. Quais sejam, o princípio da solidariedade entre espécies, em que cabe ao homem a manutenção do bem-estar e dignidade das demais seres vivos para a fruição de um ambiente ecologicamente equilibrado; bem como, o princípio da liberdade humana de manifestar-se e de ter acesso à cultura e ao entretenimento. $\mathrm{E}$, quando interesses antropocêntricos colidem com os demais fundamentos da vida, cabe ao Poder Judiciário decidir sobre a matéria e harmonizar os conflitos. 
No Brasil, casos importantes incumbiram ao Supremo Tribunal Federal a ponderação de tais princípios assegurados pela Constituição Federal de 1988. Dentre estes, encontram-se o Recurso Extraordinário $n^{\circ}$ 153.531-8 de 1997, que tem por escopo a condenação do Estado de Santa Catarina a proceder à proibição da denominada farra do boi e ou manifestações semelhantes por atos e medidas formais e práticas. No acórdão em apreço, o Ministro relator Francisco Rezek manifestou-se pela primazia dos direitos dos animais ao destacar, dizendo "Não posso ver como juridicamente correta a ideia de que em prática dessa natureza a Constituição não é alvejada. Não há aqui uma manifestação cultural com abusos avulsos; há uma prática abertamente violenta e cruel para com animais, e a Constituição não deseja isso.”, o que fica evidente a descaracterização do conceito manifestação cultural, quando esta se vale da crueldade e dos maus tratos para com os animais, seres vivos e, portanto, detentores de direitos.

Para sanar a questão em voga, o Min. Francisco Rezek finaliza mitigando o conflito ao proceder seu voto com o seguinte fundamento:

\begin{abstract}
Abstraídas as considerações metajurídicas que poderiam levar à crítica irônica da ação e, agora, do recurso extraordinário, o que temos é um claro caso de ação civil pública idônea, como a prevê a lei, para um fim legítimo. Foi ela ajuizada, dentro da unidade da nossa cultura e da nossa ordem jurídica, por instituições de certo ponto do país que, por acaso, se sensibilizaram primeiro e primeiro entenderam que a Justiça o poderia socorrer a causa da Constituição. Claros os fatos, como se passam a cada ano, essa prática se caracteriza como ofensiva ao inciso VII do art. 225 da Constituição, de tal modo que a ação civil pública deveria ter sido considerada procedente para que se determinassem às autoridades do estado de Santa Catarina as providências cabíveis.
\end{abstract}

Em oposição aos mesmos princípios postos em discurso, a Ação Direta de Inconstitucionalidade $\mathrm{n}^{\mathrm{o}}$ 2.514-7 de 2005 passa o observar a inconstitucionalidade da lei $\mathrm{n}$. 11.366/00, também do estado de Santa Catarina, que autoriza e regulamenta a criação, a exposição e a realização de "brigas de galo". Seguindo o precedente objetivo do RE nº 153.5318 de 1997, o Ministro relator Eros Grau ressalta que "ao autorizar a odiosa competição entre galos, o legislador estadual ignorou o comando contido no inciso VII do $\S 1^{\text {a }}$ do artigo 225 da Constituição do Brasil, que expressamente veda práticas que submetam os animais à crueldade."

Já no ano de 2011 a Ação Direta de Inconstitucionalidade 1.856 analisou a inconstitucionalidade da Lei $\mathrm{n}^{\circ} 2.895$ de 1998 procedente do Rio de Janeiro, que também 
versava sobre a odiosa prática das "brigas de galo", teve como relator o Min. José Celso de Mello Filho, reafirma que:

O fundamento em que se apóia a pretensão de inconstitucionalidade do diploma legislativo em referência reside na prática de atos revestidos de inquestionável crueldade contra aves das Raças Combatentes ("gallusgallus") que são submetidas a maus-tratos, em competições promovidas por infratores do ordenamento constitucional e da legislação ambiental, que transgridem, com seu comportamento delinquencial, a regra constante do inciso VII do $\S 1^{\circ}$ do art. 225 da Constituição da República.

O Ministro relator enfatiza em seu voto que a matéria é impregnada pelo alto significado ético jurídico, ressaltando que a proteção da fauna e da flora, estabelecidos pela Constituição Federal, possuem sua justificativa por sua própria razão de ser, que instiga-se pela motivação de uma necessidade imperiosa de barrar a ocorrência de ameaças que periglitam todas as formas de vida, para que seja possível defendê-las em benefício das presentes e futuras gerações. Neste ponto, o Min. Celso de Mello, implicitamente reverbera o princípio da solidariedade entre espécies, colocando os seres humanos como responsáveis pela preservação da vida além dos interesses antropocêntricos.

Em contrapartida, a Assembleia Legislativa do estado do Rio de Janeiro, ao prestar as informações que lhe foram solicitadas, manifestou-se pela improcedência da ADI, propugnando pelo reconhecimento da plena validade constitucional da norma, o que exalta o posicionamento refutado pelo texto constitucional ao argumentando que:

Em sentido lato, prossegue, a palavra fauna refere-se ao conjunto de todos os animais de uma região ou de um período geológico, abrangendo aí a fauna aquática, a fauna das árvores e de solo (insetos e microorganismos) e a fauna silvestre (animais de pêlo e de pena).

Não é de se incluírem os animais domésticos e domesticados, nem os de cativeiro, criatórios e de zoológicos particulares, devidamente legalizados, remata o emérito constitucionalista.[...]

Nesse sentido, cumpre aduzir, ao se perquirir o conteúdo semântico, o sentido normativo contido na expressão: '(...) vedada as práticas que (...) submetam os animais a crueldade', destacada na peça vestibular, verifica-se que o seu sentido é o de coibir práticas em que há ação do homem contra o animal, assim como ocorre na caça, no tiro ao pombo, na conhecida farra do boi.

$\mathrm{Na}$ hipótese do chamado 'galismo' as aves lutam sem qualquer interferência direta do homem; brigam por seu espírito atávico, nada havendo a forçá-las a combater.

Ao estabelecer argumentos favoráveis à prática, o representante do estado do Rio de Janeiro, imputa-se pela valoração do detrimento de uma espécie em favor da prerrogativa econômica e supostamente social do sádico evento. A descaracterização de seres vivos e a 
mitigação dos valores intrínsecos às espécies não humana são observáveis nestes casos em concreto.

Na mesma toada, a PEC 270 de 2016, propôs o acréscimo do parágrafo $\S 4^{\circ}$ ao art. 215 da Constituição Federal, para preservar rodeios e vaquejadas e expressões artístico-culturais decorrentes, como patrimônio cultural imaterial brasileiro, o que destaca o valor econômico dado a utilização de animais em eventos tidos como manifestações culturais, sendo tal elemento empregado como justificava indissociável da prática, e portanto, benemerente de defesa constitucional, assim como alega que:

O Manifesto à Marcha dos Vaqueiros dimensiona que atualmente existem mais de 600 mil pessoas ligadas direta ou indiretamente à vaquejada, responsáveis pela geração de emprego e renda para um país e região que vivem grave crise econômica e que, inevitavelmente, passarão a viver na marginalidade da economia e da sociedade.

Chalfun (2014), argumenta que a ecologia profunda (deep ecology) estabelece uma alteração da percepção antropocêntrica, limitando o consumo e a produção de bens e serviços às necessidades essenciais de uma sociedade, não vinculando-se a rentabilidade. Além do mais, a partir dessa teoria, o ser humano não deve colocar-se em uma hierarquia superior a outras espécies, mas sim, necessita-se que a solidariedade ressoe, sendo validada quando o respeito recíproco entre humanos atinja o alcance às demais formas de vida.

Nota-se que o valor econômico imputado aos costumes humanos transpassa a consciência por um ambiente ecologicamente equilibrado. Nesse sentido, outra Ação Direta de Inconstitucionalidade revela este embate principiológico em sua culminante controvérsia; a ADI 4.983 de 2016 analisou a inconstitucionalidade da Lei $n^{\circ} 15.299 / 2013$, a qual regulava no estado do Ceará a prática da vaquejada, que consistia na disputa entre duas duplas de vaqueiros, montados em cavalos distintos, com o propósito de derrubar um bovino, puxando-o pela cauda dentro de uma área demarcada.

A polarização dos princípios constitucionais alcança a Suprema Corte no caso supramencionado. O Min. Marco Aurélio, relator do processo, discute em seu voto os fundamentos em defesa da proteção dos animais não humanos ao descaracterizar a vaquejada como manifestação cultural, ponderando que:

[...] a crueldade intrínseca à vaquejada não permite a prevalência do valor cultural como resultado desejado pelo sistema de direitos fundamentais da Carta de 1988. O sentido da expressão crueldade" constante da parte final do inciso VII do $\S 1^{\circ}$ do artigo 225 do Diploma Maior alcança, sem sombra de 
dúvida, a tortura e os maus tratos infringidos aos bovinos durante a prática impugnada, revelando-se intolerável, a mais não poder, a conduta humana autorizada pela norma estadual atacada. No âmbito de composição dos interesses fundamentais envolvidos neste processo, há de sobressair a pretensão de proteção ao meio ambiente.

Em contrapartida, em seu voto, o Min. Edson Fachin sobreleva o polo antropocêntrico ao destacar que "numa sociedade aberta e plural, como a sociedade brasileira, a noção de cultura é uma noção construída, não é um a priori, como está na obra de Tânia Maria dos Santos. E se encontra, no nosso modo de ver, umbilicalmente ligada a uma noção mais ampla do que se tenha por meio ambiente, $[. .$.$] ". Esse posicionamento mostra uma visão da fauna, não como$ sujeito de direitos, mas como objeto a ser tutelado em benefício dos seres humanos, e, portanto, a tutela de um ambiente ecologicamente equilibrado sub rogaria-se ao direito humano de preservar suas práticas culturais, ainda que estas estejam entranhadas pela cruel sujeição de outras espécies à dor e ao sofrimento.

Por outro lado, o Min. Luís Roberto Barroso transborda em seu voto o resguardo do bem estar dos animais pela sua valoração intrínseca, ao expõe que a sociedade "tem-se evoluído para entender que a vedação da crueldade contra animais, referida no art. $225, \S 1^{\circ}$, VII da Constituição, já não se limita à proteção do meio ambiente ou mesmo apenas a preservar a função ecológica das espécies.”. Em suma, para o ministro, é necessário que proteja-se os animais contra a crueldade não apenas como uma função da tutela de outros bens jurídicos, mas, é necessário que se observe além do estabelecido pelo antropocentrismo, deve-se reconhecer a proteção de outras espécies como um valor autônomo, que enseje pela custódio por sua própria razão de ser e existir.

O posicionamento do Min. Luís Roberto Barroso corrobora com o entendimento de Sarlet (2017, p. 77) ao instruir sobre o princípio da Dignidade do Animal Não Humano e da Vida em Geral, o autor destaca que o "dever moral de um tratamento não cruel dos animais deve buscar, portanto, o seu fundamento não mais na dignidade humana ou na compaixão humana, mas sim na própria dignidade inerente às existências dos animais não humanos.”.

Por maioria e nos termos do voto do Ministro relator Marco Aurélio, o Supremo Tribunal Federal decidiu procedência da Ação Direta de Inconstitucionalidade contra a Lei 15.299/2013. A partir do caso em questão, o Deputado Federal Ricardo Tripoli, em seu voto em separado na PEC 304 de 2017, arrazoa ao explanar que Supremo Tribunal Federal cumpriu seu papel de guardião da Constituição Federal, reconhecendo as características intrínsecas da vaquejada como sendo de submissão dos animais a crueldade, declarando, portanto, a inconstitucionalidade da lei cearense. 
Sob a ótica do parlamentar, a Suprema Corte não se limitou a declarar a inconstitucionalidade de uma atividade qualquer considerada como violenta, mas observou o tradicional evento nordestino justamente como uma manifestação cultural, nos termos do art. 215 da Constituição. E ainda assim, tornou-a sem efeitos ao decretá-la como inconstitucional, devendo esta prática, portanto, observar a obrigação perpetrada constitucionalmente de não resignação dos animais não humanos à crueldade.

\section{NORMAS CONSTITUCIONAIS FADADAS À INCONSTITUCIONALIDADE: RETROCESSO AMBIENTAL PERPETRADO PELA EMENDA CONSTITUCIONAL 96/2017}

Assegurado pela Constituição Federal de 1988, o direito a um ambiente ecologicamente equilibrado é um direito fundamental que deve ser garantido pelo Estado, tendo em vista o seu impacto direto no princípio da Dignidade da Pessoa Humana, afetando tanto os seres humanos quanto os animais não humanos. Nesse caso, segundo De Santana Gordilho (2018) "a depender do paradigma utilizado, os animais podem ser considerados objeto de direito ou sujeito de direito. Na primeira hipótese, eles são considerados seres sensíveis ou sencientes e, por esta condição, merecem uma proteção diferenciada em nosso ordenamento jurídico."

Sobre a evolução dos conceitos que vislumbram pela tutela dos direitos dos animais, Campello (2018) deixa inequívoca a atual vivência em uma era de direitos mais que dinâmicos, sendo estas ferramentas de transformação da realidade nacional e internacional. E, diante da existência de conflitos principiológicos que ocorrem no ordenamento jurídico nacional, faz-se basilar a interposição da racionalidade humana sob a vertente do princípio da solidariedade entre espécies, utilizando da suposta superioridade destes como um instrumento equiparador em favor dos demais animais não humanos, seres incapazes de manifestar-se em sua defesa.

O primeiro caso de prática tida como manifestação cultural que usufruía do sofrimento animal como base do entretenimento humano chegou ao Supremo Tribunal Federal sob a Recurso Extraordinário N. 153.531-8, Santa Catarina, julgado em 04 de fevereiro de 1997, o qual por maioria dos votos foi dado provimento ao recurso nos termos do voto do relator que destacou a Farra do Boi como "uma prática abertamente violenta e cruel para com animais" e não desejável pela Constituição Federal. 
Posterior ao emblemático caso da Farra do Boi, outra importante Ação Direta de Inconstitucionalidade, pleiteada pela declaração de inconstitucionalidade da lei n. 11.366/00, também do estado de Santa Catarina, que autorizava e regulava a criação, a exposição e a realização de brigas de galo, foi julgada a ADI n. 2.514-7 pelo Supremo Tribunal FederaL em 29 de junho de 2005. E por unanimidade dos votos, a norma que regulamenta a Briga de Galo foi declarada inconstitucional sob os fundamentos do Ministro Relator Eros Grau, que destacou que "ao autorizar a odiosa competição entre galos, o legislador estadual ignorou o comando contido no inciso VII do $\S 1^{\circ}$ do artigo 225 da Constituição do Brasil, que expressamente veda práticas que submetam os animais à crueldade.

Correspondente a ADI n. 2.514-7/2005, a Suprema Corte apreciou a Ação Direta de Inconstitucionalidade n. 1.856 em 26 de maio de 2011, para declarar a inconstitucionalidade da Lei n. 2.895, de 20 de março de 1998, do estado do Rio de Janeiro que também positivou a prática da Briga de Galo. A ADI n. 1.856 foi julgada improcedente, por unanimidade dos votos, nos termos do voto do Ministro Relator Celso de Mello que fundamentou arguindo que a pretensão "reside na prática de atos revestidos de inquestionável crueldade contra aves das Raças Combatentes (gallus-gallus) que são submetidas a maus-tratos" transgredindo a regra constante do inciso VII do $\S 1^{\circ}$ do artigo 225 da Constituição da República.

Em 06 de outubro de 2016, julgou-se no Supremo Tribunal Federal a Ação Direta de Inconstitucionalidade n. 4.983, por maioria dos votos declarou inconstitucional a Lei n. 15.299 de 08 de janeiro de 2013, do estado do Ceará, que regulamenta a Vaquejada como prática desportiva e cultural. O Ministro Relator Marco Aurélio fundamentou seu voto alegando que "a crueldade intrínseca à vaquejada não permite a prevalência do valor cultural como resultado desejado pelo sistema de direitos fundamentais da Carta de 1988", sobressaindo-se no âmbito de interesses fundamentais envolvidos no processo a pretensão de proteção do meio ambiente em face ao direito humano de manifestar-se culturalmente.

Nesta toada, nota-se diante dos julgados pertinentes à matéria, que o Supremo Tribunal Federal constituiu ao longo dos anos um sólido posicionamento favorável à proteção e resguardo do direito dos animais de não serem submetidos à crueldade em face ao direito humano de manifestar-se culturalmente. Contudo, em colisão com a decisão da Suprema Corte, a Emenda Constitucional 96, de 06.06.2017, instaurou como não crueis as práticas desportivas que utilizem animais, condicionando que, para tanto, estas sejam caracterizadas como manifestações culturais, inserindo o controvertido $\S 7^{\circ}$ ao art. 225 da Constituição Federal de 1988, que expressa: 
$\S 7^{\circ}$ Para fins do disposto na parte final do inciso VII do $\S 1^{\circ}$ deste artigo, não se consideram cruéis as práticas desportivas que utilizem animais, desde que sejam manifestações culturais, conforme o $\S 1^{\circ}$ do art. 215 desta Constituição Federal, registradas como bem de natureza imaterial integrante do patrimônio cultural brasileiro, devendo ser regulamentadas por lei específica que assegure o bem-estar dos animais envolvidos.

Evidencia-se, portanto, a incidência do efeito backlash em desfavor do julgamento da ADI 4.983 de 2016, que reconheceu a inconstitucionalidade da vaquejada por esta infringir os preceitos constitucionais de submissão de animais a práticas crueis, bem como o da garantia humana a um ambiente ecologicamente equilibrado, resguardados pelo art. 225 e incisos da Constituição Federal de 1988. Esse efeito pode ser compreendido como uma reação negativa (popular, institucional) contra determinada decisão, típica do Constitucionalismo Democrático (MARINHO, 2018).

Tal posicionamento rebate todos os esforços pela proteção e amparo aos direitos dos animais, como anteriormente previa expresso pela Constituição. Cabe ressaltar que o $7^{\circ}$ parágrafo inserido não aniquila, porém, flexibiliza a tutela dos animais não humanos de não serem submetidos à crueldade; é uma fenda que expõe seres vivos à dor física e sofrimento psíquico e, sobretudo, não se justifica pelo seu argumento mercadológico e antropocêntrico do bem estar humano de poder manifestar-se culturalmente. Entre as imensas e diversificadas possibilidades dos seres humanos exteriorizarem suas expressões culturais e tradições, hodiernamente, não é tolerável a uma sociedade evoluída utilizar-se do sádico uso de animais nestas manifestações.

Como observado, a referida emenda derrubou o entendimento sobre a matéria estabelecido pela Suprema Corte e, consequentemente, outras Ações Diretas de Inconstitucionalidade que versavam sobre a temática tiveram seu objeto prejudicado, culminando no retrocesso da luta em defesa dos direitos dos animais não humanos de não serem submetidos à crueldade. Dessa maneira, na Ação Direta de Inconstitucionalidade n. 5713, decidida de forma monocrática no dia 2 de março de 2018, ao versar contra a Lei ${ }^{\circ} 10428$, de 20 de janeiro de 2015, do estado da Paraíba, pode-se notar a impossibilidade do Supremo Tribunal Federal de aplicar sua jurisprudência ao destacar que:

A promulgação da Emenda de $n^{\circ}$ 96, em 6 de junho de 2017, implicou alteração superveniente do parâmetro de controle. Apesar de mantida a redação do inciso VII do $\S 1^{\circ}$ do artigo 225 da Constituição Federal, incluiuse o $\S 7^{\circ}$, a revelar não serem cruéis as práticas desportivas que utilizem 
animais, desde que reconhecidas como manifestações culturais e nas condições que especifica.

Na mesma toada, a Ação Direta de Inconstitucionalidade n. 5711 interposta contra a Lei n 1906, de 19 de junho de 2015, do estado do Amapá, também teve seu objeto deturpado pela supramencionada emenda e, dessa forma, o Supremo Tribunal Federal fundamenta em sua decisão monocrática que "Mediante ato do poder constituinte derivado, modificou-se, de forma substancial, o tratamento constitucionalmente conferido à vaquejada, ficando prejudicada a análise desta ação, observada a jurisprudência do Supremo.”.

Além do mais, normas que anteriormente tiveram seu conteúdo manifestamente decretados como inconstitucionais pela Suprema Corte, hodiernamente, após emenda constitucional passaram a nutrir forças no ordenamento jurídico nacional não apenas pelo direito humano à cultura e ao entretenimento, mas, principalmente pelo desenvolvimento econômico implícito em tais manifestações culturais. Nessa perspectiva, é possível observar que além da instituição de novas leis regulamentadoras de eventos como os rodeios e vaquejadas, houve a ampliação da abrangência de normas já existente sobre o assunto.

À vista disso, a Lei ${ }^{\circ}$ 13.364, de 29 de novembro de 2016, abordava em seu corpo a elevação do Rodeio e da Vaquejada, bem como as respectivas expressões artístico-culturais, à condição de manifestação cultural nacional e de patrimônio cultural imaterial, possuindo então seu conteúdo atingido pela inconstitucionalidade determinada pelo Supremo Tribunal Federal. Após a Emenda Constitucional 96/2017, e com a perda dos efeitos da decisão que resguardava os direitos e proteções contra à crueldade aos animais não humanos, além de força para aplicação de seu conteúdo, tal Lei foi alterada e teve sua abrangência ampliada pela Lei $\mathrm{n}^{\circ}$ 13.873, de 17 de setembro de 2019, incluindo em sua disposição o laço, bem como as respectivas expressões artísticas e esportivas, a fim de ascender essas atividades à condição de bem de natureza imaterial integrante do patrimônio cultural brasileiro.

A partir de então, nota-se que os esforços pela tutela jurídica dos direitos dos animais, ainda que resguardada em instâncias superiores do judiciário, frustra-se ao colidir com os interesses econômicos e sociais humanos. Esse efeito backlash sobre a matéria é o retrato angariado pelo antropocentrismo, marcado pelo uso e instrumentalização indiscriminada tanto dos animais não humanos quanto do meio ambiente como um todo, em prol do lucro incessante e do gozo de suas tradições para satisfação de um bem estar coletivo e exclusivamente humano.

Porém, em contrapartida, a Ação Direta de Inconstitucionalidade n. 5.728 de 2017, proposta pelo Fórum Nacional de Proteção e Defesa Animal, tramita na Suprema Corte e 
carrega a alegação de que a Emenda Constitucional 96/2017 violou o cerne do direito ao meio ambiente equilibrado, sob a ótica da proibição do tratamento cruel aos animais não humanos, resguardados pelo artigo 225, parágrafo $1^{\circ}$, inciso VII, da Constituição Federal de 1988. Nesse sentido, o controle de constitucionalidade a que será submetida a Emenda Constitucional 96/2017 reacende a possibilidade de correção de um significativo retrocesso estabelecido sobre a tutela dos animais não humanos.

Além do mais, é importante ressaltar que o direito ao meio ambiente ecologicamente equilibrado trata-se, sobretudo, de um direito fundamental com conteúdo implícito em normas constitucionais. De acordo com Cunha (2015) "o direito ao meio ambiente ecologicamente equilibrado possui status de cláusula pétrea, não podendo, nessa condição, ser objeto de deliberação, a proposta de emenda tendente a aboli-lo, conforme artigo 60, $\S 4^{\circ}$ inciso IV da Constituição Federal de 1988."

Sarlet (2018) aponta que a doutrina majoritária aborda como lição que "as "cláusulas pétreas" de uma Constituição não objetivam a proteção dos dispositivos constitucionais em si, mas, sim dos princípios neles plasmados, não podendo estes ser esvaziados por uma reforma constitucional.”. Portanto, mostra-se fadada à inconstitucionalidade a alteração por emenda constitucional do dispositivo que resguarda tanto o direito humano a um ambiente ecologicamente equilibrado quanto o direito do animal não humano de não ser submetido a atos subversivos de crueldade, ainda que estes ocorram sob a justificativa de se garantir a constitucionalidade do direito humanos de manifestar-se culturalmente.

Cumpre destacar, que por todos os pontos expostos, ainda que avanços significativos tenham ocorrido no ordenamento jurídico nacional, com base nas decisões emplacadas à Suprema Corte, ainda o cenário mostra-se hostil quando se tratam de conflitos principiológicos que colocam em choque os direitos dos animais e os interesses estritamente humanos. Ainda que sejam reconhecidos como sujeitos passíveis de tutela jurisdicional, a ação humana mostrase contundente ao buscar saídas que desvirtuem direitos garantidos aos animais, assim como vislumbrado pela Emenda Constitucional 96/2017, o que coloca em evidência a importância da luta contra a crueldade estabelecida aos animais não humanos, seres sensíveis e detentores de direitos.

\section{CONCLUSÃO}

Ante o exposto, apresentou-se evidente que conflitos importantes emergem quando se tem em questão valores constitucionais em discussão. Tal controvérsia encontra-se diante do 
choque de princípios resguardados constitucionalmente como direitos fundamentais, como: o direito à manifestação cultural e ao lazer, em afronta ao direito dos animais de não serem submetidos a tratamentos crueis.

Nesse ínterim, em uma abordagem regulamentar sobre o tema, constatou-se que o arcabouço normativo sobre os direitos dos animais não humanos diante da crueldade e interesses subjetivamente humanos sofreram tímidos avanços. A partir da Resolução $\mathrm{n}^{\circ}$ 1.236, publicada no Diário Oficial pelo Conselho Federal de Medicina Veterinária no ano de 2018, como exemplo, consolidou-se conceitos ao estabelecer definições e diferenciações entre os maus-tratos, a crueldade e os abusos praticados contra os animais não humano. Desse modo, atinge-se como essência a pacificação e uniformização do uso e identificação destes termos, ora relativizados.

Além do mais, o direito ao ambiente ecologicamente equilibrado é um direito fundamental que deve ser garantido pelo Estado, tendo em vista o seu impacto direto no princípio da Dignidade da Pessoa Humana, afetando tanto os seres humanos quanto os animais não humanos. E, ao utilizar animais não humanos em manifestações culturais, que possuem como fim apenas a satisfação de prazeres exclusivamente humanos, coloca-se em xeque princípios constitucionais e fundamentais. E, quando interesses antropocêntricos colidem com os demais fundamentos da vida, cabe ao Poder Judiciário decidir sobre a matéria e harmonizar os conflitos.

No Brasil, casos importantes foram encarregados ao Supremo Tribunal Federal à ponderação desses princípios assegurados pela Constituição Federal. Diante dos julgados pertinentes à matéria, o Supremo Tribunal Federal constituiu ao longo dos anos um sólido posicionamento favorável à proteção e ao resguardo dos direitos dos animais de não serem submetidos à crueldade em face ao direito humano de manifestar-se culturalmente. Contudo, em contrapartida às decisões da Suprema Corte, a Emenda Constitucional 96, de 06.06.2017, instituiu como não crueis as práticas desportivas que utilizem animais, condicionando que, para tanto, estas sejam caracterizadas como manifestações culturais.

Com a aprovação da Emenda Constitucional 96, tem-se, portanto, a caracterização do efeito backlash sobre a matéria. Defronte à constitucionalização do retrocesso quanto aos direitos dos animais humanos não humanos, observa-se o retrato da sobreposição de valores antropocêntricos, marcado pelo uso e instrumentalização indiscriminada tanto dos animais não humanos quanto do meio ambiente como um todo, em prol de interesses singulares destacados por tradições que possuem como finalidade a satisfação de um bem estar coletivo e exclusivamente humano. 
A partir de então, evidencia-se a fragilidade da tutela dos direitos dos animais perante os antropocêntricos interesses humanos, que ao se chocarem, deixam manifesta a prevalência destes em face ao sofrimento e à instrumentalização de seres vivos, sencientes e, também, detentores de direitos. Desse modo, a possibilidade de uma tutela mais rígida sobre o bem-estar do animal não-humano no ordenamento jurídico nacional em face à proteção constitucional da manifestação cultural dos cidadãos brasileiros é concebível, desde que afastadas as intenções de retrocesso pela aplicação do princípio do não retrocesso ambiental e garantindo-se a condição de cláusula pétrea ambiental como impedimento ao poder reformador.

E para que seja alcançado o amparo jurídico aos animais não humanos, é necessário que se atribua à espécie humana, pelo princípio da solidariedade entre espécies, o dever de reconhecer a outorga valorativa intrínseca dos seres vivos, respeitando, desse modo, tanto a presença fática quanto a existência jurídica de todos os indivíduos, independentemente de sua condição racional, dirimindo a hierarquização das espécies e a sobreposição de valores econômicos e antropocêntricos interesses exclusivamente humanos.

\section{REFERÊNCIAS}

BRASIL. Câmara dos Deputados. Proposta de Emenda à Constituição 270/2016 Acrescenta o parágrafo $\S 4^{\circ}$ ao art. 215 da Constituição Federal. Disponível em: https://www.camara.leg.br/proposicoesWeb/fichadetramitacao?idProposicao=2115233. Acessado em: 09 de abril de 2019.

BRASIL. Câmara dos Deputados. Proposta de Emenda à Constituição 304/2017 Acrescenta § $7^{\circ}$ ao art. 225 da Constituição Federal. Disponível em: https://www.camara.leg.br/proposicoesWeb/fichadetramitacao?idProposicao=2123843. Acessado em: 09 de abril de 2019.

BRASIL. Conselho Federal De Medicina Veterinária. Define e caracteriza crueldade, abuso e maus-tratos contra animais vertebrados, dispõe sobre a conduta de médicos veterinários e zootecnistas e dá outras providências. Resolução n. 1236, de 23 de abril de 2019. Disponível em: http://portal.cfmv.gov.br/lei/download-arquivo/id/1096. Acesso em: 03 de maio de 2019.

BRASIL. Constituição (1988). Emenda constitucional no 96, de 6 de junho de 2017. Acrescenta $\S 7^{\circ}$ ao art. 225 da Constituição Federal para determinar que práticas desportivas que utilizem animais não são consideradas cruéis, nas condições que especifica. Brasília, DF, DOU 7.6.2017.

BRASIL. Lei $n^{o}$ 13.364, de 29 de novembro de 2016. Disponível em: http://www.planalto.gov.br/ccivil_03/_ato2015-2018/2016/lei/L13364.htm. Acessado em: 23 de março de 2019.

BRASIL. Lei $n^{o}$ 13.873, de 17 de setembro de 2019. Disponível em: http://www.planalto.gov.br/ccivil_03/_Ato2019-2022/2019/Lei/L13873.htm. Acessado em: 23 
de março de 2019.

BRASIL. Supremo Tribunal Federal. Relator Ministro Celso de Mello. Ação Direta de Inconstitucionalidade n. 1.856 Rio de Janeiro. Diário da Justiça. Disponível em: http://redir.stf.jus.br/paginadorpub/paginador.jsp?docTP=AC\&docID=628634 . Acessado em: 23 de março de 2019.

BRASIL. Supremo Tribunal Federal. Relator Ministro Eros Grau. Ação Direta de Inconstitucionalidade 2.514-7, Santa Catarina. 2005. Diário da Justiça. Disponível em: http://redir.stf.jus.br/paginadorpub/paginador.jsp?docTP=AC\&docID=266833. Acessado em: 23 de março de 2019.

BRASIL. Supremo Tribunal Federal. Relator Ministro Marco Aurélio. Ação Direta de Inconstitucionalidade n. 4.983 Ceará. 2016. Diário da Justiça. Disponível em: http://redir.stf.jus.br/paginadorpub/paginador.jsp?docTP=TP\&docID=12798874. Acessado em: 23 de março de 2019.

BRASIL. Supremo Tribunal Federal. Relator Ministro Marco Aurélio. Ação Direta de Inconstitucionalidade n. 5.711 Amapá. Diário da Justiça. Disponível em: http://portal.stf.jus.br/processos/downloadPeca.asp?id=313825263\&ext=.pdf. Acessado em: 23 de março de 2019.

BRASIL. Supremo Tribunal Federal. Relator Ministro Marco Aurélio. Ação Direta de Inconstitucionalidade n. 5.713 Paraíba. Diário da Justiça. Disponível em: https://portal.stf.jus.br/processos/downloadPeca.asp?id=313825267\&ext=.pdf. Acessado em: 23 de março de 2019.

BRASIL. Supremo Tribunal Federal. Relator Ministro Dias Toffoli. Ação Direta de Inconstitucionalidade n. 5.728 Distrito Federal. Diário da Justiça. Disponível em: http://portal.stf.jus.br/processos/downloadPeca.asp?id=313825263\&ext=.pdf. Acessado em: 23 de março de 2019.

BRASIL. Supremo Tribunal Federal. Relator Ministro Marco Aurélio. Recurso Extraordinário $\mathrm{n}^{\circ}$ 153.531-8 Santa Catarina. Diário da Justiça. Disponível em: http://redir.stf.jus.br/paginadorpub/paginador.jsp?docTP=AC\&docID=211500. Acessado em: 23 de março de 2019.

BENTHAM, Jeremy. An introduction to the principles of morals and legislation. Londres: W. Pickering, 1823.

BROOM, D.M.; MOLENTO, C.F.M. Bem-estar animal: conceito e questões relacionadas revisão. Archives of Veterinary Science. v. 9, n. 2, p. 1-11, 2004.

CASTRO JUNIOR, Marco Aurélio de; VITAL Aline de Oliveira. Direitos dos animais e a garantia constitucional de vedação à crueldade. Salvador: RBDA, v.10, n. 18 jan- abr 2015.

CABRAL, Mário André Machado; MASCARENHAS, Fábio Sampaio. Meio ambiente, constituição e direito econômico: Argumentos econômicos versus proteção animal. Revista Brasileira de Direito Animal, v. 13, n. 3, 2018.

CAMPELLO, Lívia Gaigher Bósio. A era da afirmação dos direitos dos animais no cenário global e seu fundamento na solidariedade entre espécies. Revista Brasileira de Direito Animal, 
v. 13, n. 2, 2018.

COUTINHO, Ana Filipa Oliveira Samúdio Viana. Subjetividade na avaliação da dor animal. 2012. Tese de Doutorado. Universidade Técnica de Lisboa. Faculdade de Medicina Veterinária.

CHALFUN, Mary. Paradigmas filosóficos-ambientais e o direito dos animais. Revista Brasileira de direito animal, v. 5, n. 6, 2014.

CUNHA, Estela Pamplona. O direito fundamental ao meio ambiente ecologicamente equilibrado na ordem constitucional brasileira. Brasília: EDB/ IDP, 2015.

Declaração Universal dos Direitos do Animal - Unesco. Acessado em: 10 de abril de 2019. Disponível em: http://www.apasfa.org/leis/declaracao.

GORDILHO, Heron Santana; MOURA BORGES, Daniel. Direito Animal e a Inconstitucionalidade da 96 a Emenda à Constituição Brasileira. Revista Sequência, v. 39, n. $78,2018$.

GORDILHO, Heron José de Santana; SANTOS JÚNIOR, Cristóvão José dos. O STATVS JURÍDICO SVI GENERIS DOS ANIMAIS NO CORPVS IVRIS CIVILIS. Revista Juridica, [S.1.], v. 1, n. 54, p. 116 - 144, mar. 2019. ISSN 2316-753X. Disponível em: <http://revista.unicuritiba.edu.br/index.php/RevJur/article/view/3303/371371796>. Acesso em: 23 abr. 2020. doi:http://dx.doi.org/10.21902/revistajur.2316-753X.v1i54.3303.

GORDILHO, Heron Santana. Habeas-Corpus em favor de Jimmy, Chimpanzé preso no Jardim Zoológico de Niterói-Rio de Janeiro. Revista Brasileira de Direito Animal, v. 5, n. 6, 2014.

FAVRE, David. O ganho de força dos direitos dos animais. Revista Brasileira de Direito Animal, v. 1, n. 1, 2014.

FRANCIONE, Gary L. Animal Rights and Animal Welfare. Rutgers L. Rev. 397, 48, 1996.

FEIJÓ, Anamaria Gonçalves dos Santos; SANTOS, Cleopas Isaías do; GREY, Natália de Campos. O animal não-humano e seu status moral para a ciência e o direito no cenário brasileiro. Salvador: RBDA, ano 5, v. 6, jan - jun 2010.

FELIZOLA, Milena Britto. A cultura do entretenimento com animais e o entendimento dos tribunais pátrios. Salvador: RBDA, ano 6, v.9, jul - dez 2011.

GRUBBA, Leilane Serratine; CADORE, Caroline BM. Proteção ao meio ambiente, aos animais e o direito à cultura: a aplicação da fórmula do peso refinada de robert alexy. Revista Brasileira de Direito Animal, v. 12, n. 02, 2017.

LEVENDA, Kelly. Science-Based Farmed Animal Welfare Laws for the U.S. Journal of Animal \& Natural Resource Law, vol. 13. Resource L. 93.

LODER, Reed Elizabeth. Animal Dignity. Animal, L.1, 23, 2016.

MARINHO, Rodrigo Fonseca; MARTINS, Julia Parreiras. Os poderes judiciário e legislativo no caso da vaquejada:“efeito backlash”. Athenas, Ano VII, vol. I, 2018.

MARTINI, Sandra Regina; AZEVEDO, Juliana Lima de. Sobre a vedação constitucional de 
crueldade contra animais. RBDA, Salvador, V.13, N. 01, PP. 193-215, Jan-Abr 2018.

NUSSBAUM, Martha C. Frontiers of justice: Disability, nationality, species membership. Harvard University Press, 2009.

REGAN, Tom; VAZIAS, Jaulas. Encarando o desafio dos direitos animais. Porto Alegre, RS: Lugano Editora, 2006.

RODRIGUES, Nina Tricia Disconzi; SPAREMBERGER, Raquel Fabiana Lopes; CALGARO, Cleide (Orgs.). Direito constitucional ecológico. Porto Alegre, RS: Editora Fi, 2017. 501 p.

SARLET, Ingo Wolfgang. A eficácia dos direitos fundamentais: uma teoria geral dos direitos fundamentais na perspectiva constitucional. 13. ed. Porto Alegre, RS: Livraria do Advogado Editora, 2018.

SARLET, Ingo Wolfgang; FENSTERSEIFER, Thiago. princípios do direito ambiental. 2. ed. São Paulo, SP: Saraiva, 2017.

SINGER, Peter. Libertação animal. Tradução: Marly Winckler; Marcelo Brandão Cipolla. São Paulo, SP: WMF Martins Fontes, 2010, p. 20.

TOLEDO, Maria Izabel Vasco de. A tutela jurídica dos animais no Brasil e no direito comparado. Salvador: RBDA, ano 7, v. 11, jul - dez 2012.

TUGLIO, Vânia. Espetáculos públicos e exibição de animais. Revista Brasileira de Direito Animal, v. 1, n. 1, 2014. 